OPEN ACCESS

Edited by:

Daniel Yero,

Institute of Biotechnology and Biomedicine (IBB), Spain

Reviewed by:

Antonio Oliver,

Hospital Universitario Son Espases,

Spain

Irene Bianconi,

University of Trento, Italy

Veronica Godoy,

Northeastern University, United States

*Correspondence:

Patricia Severino

patricia.severino@einstein.br

Specialty section:

This article was submitted to

Evolutionary and Genomic

Microbiology,

a section of the journal

Frontiers in Microbiology

Received: 25 February 2019 Accepted: 21 June 2019

Published: 10 July 2019

Citation:

Migliorini $L B$, Brüggemann $H$, de Sales RO, Koga PCM,

de Souza AV, Martino MDV,

Galhardo RS and Severino P (2019) Mutagenesis Induced by Sub-Lethal

Doses of Ciprofloxacin: Genotypic and Phenotypic Differences Between the Pseudomonas aeruginosa Strain

PA14 and Clinical Isolates.

Front. Microbiol. 10:1553.

doi: 10.3389/fmicb.2019.01553

\section{Mutagenesis Induced by Sub-Lethal Doses of Ciprofloxacin: Genotypic and Phenotypic Differences Between the Pseudomonas aeruginosa Strain PA14 and Clinical Isolates}

\author{
Letícia Busato Migliorini', Holger Brüggemann'2, Romario Oliveira de Sales', \\ Paula Célia Mariko Koga ${ }^{3}$, Andrea Vieira de Souza ${ }^{1}$, Marines Dalla Valle Martino ${ }^{3}$, \\ Rodrigo S. Galhardo ${ }^{4}$ and Patricia Severino ${ }^{1 *}$ \\ ${ }^{1}$ Hospital Israelita Albert Einstein, Albert Einstein Research and Education Institute, São Paulo, Brazil, ${ }^{2}$ Department \\ of Biomedicine, Aarhus University, Aarhus, Denmark, ${ }^{3}$ Hospital Israelita Albert Einstein, Laboratorio Clinico, São Paulo, \\ Brazil, ${ }^{4}$ Departamento de Microbiologia, Instituto de Ciências Biomédicas, Universidade de São Paulo, São Paulo, Brazil
}

Bacterial resistance is a severe threat to global public health. Exposure to sub-lethal concentrations has been considered a major driver of mutagenesis leading to antibiotic resistance in clinical settings. Ciprofloxacin is broadly used to treat infections caused by Pseudomonas aeruginosa, whereas increased mutagenesis induced by sub-lethal concentrations of ciprofloxacin has been reported for the reference strain, PAO1, in vitro. In this study we report increased mutagenesis induced by sub-lethal concentrations of ciprofloxacin for another reference strain, PA14-UCBPP, and lower mutagenesis for clinical isolates when compared to the reference strain. This unexpected result may be associated with missense mutations in imuB and recX, involved in adaptive responses, and the presence of Pyocin S2, which were found in all clinical isolates but not in the reference strain genome. The genetic differences between clinical isolates of $P$. aeruginosa and the reference PA14-UCBPP, often used to study $P$. aeruginosa phenotypes in vitro, may be involved in reduced mutagenesis under sub-lethal concentrations of CIP, a scenario that should be further explored for the understanding of bacterial fitness in hospital environments. Moreover, we highlight the presence of a complete umuDC operon in a $P$. aeruginosa clinical isolate. Even though the presence of umuDC did not contribute to a significant increase in mutagenesis, it highlights the dynamic exchange of genetic material between bacterial species in the hospital environment.

Keywords: Pseudomonas aeruginosa, bacterial resistance, umuDC, ciprofloxacin, induced mutagenesis

\section{INTRODUCTION}

Bacterial resistance is a major threat to public health worldwide. Clinically relevant antimicrobial resistance has been associated with bacterial exposure to high concentrations of antibiotics selecting pre-existing resistant variants in the population (Andersson and Hughes, 2014). On the other hand, sub-lethal concentrations of antibiotics due to inappropriate use of antibiotics in human 
and veterinary medicine and agriculture may lead to changes in the transcription of bacterial genes which contribute to the adaptation and antimicrobial resistance (Kummerer, 2003; Gullberg et al., 2011; Laureti et al., 2013; Mathieu et al., 2016).

Among genes involved in adaptive responses, the SOS regulon and $u m u D C$, are activated in response to DNA damage and encode error-prone polymerases involved in DNA translesion synthesis (TLS) and mutagenesis (Blazquez et al., 2006; Cirz et al., 2006; Friedberg et al., 2006; Baharoglu and Mazel, 2011; Thi et al., 2011). In Escherichia coli, damage-induced mutagenesis is heavily dependent on TLS polymerase V (PolV) encoded by umuDC genes (Elledge and Walker, 1983; Shinagawa et al., 1983; Reuven et al., 1999; Tang et al., 1999). Both, in vitro and in vivo studies have shown that the UmuDC complex is required for efficient TLS (Tippin et al., 2004). However, in Pseudomonas spp., Mycobacterium tuberculosis, and Caulobacter crescentus, that do not seem to carry the umuDC operon, imuAB-dnaE2 have been implicated in SOS damage-induced mutagenesis (Galhardo et al., 2005; Cirz et al., 2006; Koorits et al., 2007; Warner et al., 2010). Both operons, umuDC and imuAB-dnaE2, are actively transcribed in TLS polymerase upon exposure to antibiotics such as ciprofloxacin (CIP). CIP inhibits the activity of DNA gyrase and topoisomerase II, triggering a genotoxic effect in bacteria (Drlica and Zhao, 1997; Blazquez et al., 2006; Cirz et al., 2006; O'Sullivan et al., 2008; Dörr et al., 2009). CIP is widely used in the treatment of infections caused by $P$. aeruginosa and varying concentration gradients may be observed in body compartments due to pharmacokinetics (Van Bambeke et al., 2005). For example, sub-lethal concentrations of antibiotics are frequently found in the lungs of patients with cystic fibrosis, where the increased viscosity of the lung mucus decreases the bioavailability of the drug (Moriarty et al., 2007; Ciofu et al., 2010; Jorgensen et al., 2013; Nair et al., 2013; Bhagirath et al., 2016). Additionally, increased mutagenesis induced by sub-minimum inhibitory concentration (MIC) of CIP has been reported, in vitro, for the reference strain PAO1 (Cirz et al., 2005; Torres-Barcelo et al., 2015; Wassermann et al., 2016; Valencia et al., 2017).

In a previous work by our group we reported clinical isolates of $P$. aeruginosa harboring umuDC-like sequences (Brüggemann et al., 2018). Here, we evaluate the mutagenesis induced by subMIC concentrations of CIP in clinical isolates, including a strain carrying the $u m u D C$ operon. In addition, we present a detailed description of the genomic location of these sequences, providing evidences of their insertion in $P$. aeruginosa genomes. This work aims to add to the knowledge on how genetic traits may impact mutagenesis in $P$. aeruginosa as well as differences between reference strains and clinical isolates regarding important aspects for human health.

\section{METHODS}

\section{Strains}

The clinical isolates used herein have been previously described by Brüggemann et al. (2018). We selected three isolates from bronchoalveolar lavage (HIAE_PA11, HIAE_PA14 e
HIAE_PA10) and three isolates from blood (HIAE_PA06, HIAE_PA12 and HIAE_PA15) (SisGen number A0DD69A) that were susceptible to CIP as determined by the Vitek system (Table 1); all these strains, except for HIAE_PA10, did not harbor $u m u D C$-like sequences. We chose the reference strain PA14-UCBPP, which does not harbor $u m u D C$, similarly to PAO1 (Cirz et al., 2006; Rybenkov, 2014), in order assess mutagenesis induced by sub-MIC of CIP in an additional reference strain and compare these results with clinical isolates. There was no clonal relatedness between clinical isolates, as previously determined by multi-locus sequence typing (MLST) analysis (Brüggemann et al., 2018), thus minimizing the hypothesis that the observed results are characteristic of a specific clone.

\section{Minimum Inhibitory Concentration}

The MIC for CIP was estimated for all strains of $P$. aeruginosa using the broth microdilution method according to Clinical Laboratory Standards International (CLSI) recommendations (M100-S24) with the Mueller-Hinton culture medium (BD Difco). In this study the MIC is defined as the lowest antibiotic concentration in which there was no bacterial growth. The inoculum of each strain was diluted to $5 \times 10^{6}$ colony forming units (CFUs)/mL and $10 \mu \mathrm{L}$ of this dilution was dispensed into multiwell dishes (96 wells) containing $100 \mu \mathrm{l}$ of the serial dilution of CIP. The multiwell dishes were incubated at $37^{\circ} \mathrm{C}$ for $18 \mathrm{~h}$. The assays were carried out in triplicates and results were interpreted according to the (Clinical and Laboratory Standards Institute [CLSI], 2016).

\section{Mutation Frequency}

The mutation frequency (Number of mutants $/ \mathrm{mL}$ ) was determined for all strains by the selection method based on the appearance of Fosfomycin (FOS) resistant mutants. In FOS resistant $\left(\mathrm{FOS}^{\mathrm{R}}\right)$ strains, mutations may comprise insertions, deletions and substitutions of nitrogenous bases that lead to loss of function of the $g l p T$ gene. This gene encodes a glycerol-3-phosphate permease, which is the only known protein responsible for the entry of FOS into $P$. aeruginosa (Castaneda-Garcia et al., 2009). The mutagenesis assay was performed as described by Blazquez et al. (2006). One single colony from each strain was inoculated into $5 \mathrm{ml}$ Luria-Bertani (BD Difco) broth and incubated at $37^{\circ} \mathrm{C}$ overnight at $200 \mathrm{rpm}$. The culture was diluted 1: 1000 (Final volume $=50 \mathrm{~mL}$ ) in LB medium and incubated at $37^{\circ} \mathrm{C}, 200 \mathrm{rpm}$, until $\mathrm{OD}_{600}$ of 0.25 . Then, $10 \mathrm{~mL}$ of this culture were divided into two flasks, one inoculum for control (spontaneous mutagenesis) and the other inoculum for treatment with CIP (induced mutagenesis). The antibiotic concentration used corresponds to $0.5 \times$ MIC of $\mathrm{CIP}$. Cultures were incubated overnight at $37^{\circ} \mathrm{C}$ at $200 \mathrm{rpm}$. Samples were then serially diluted and plated on solid LB medium without antibiotics to estimate the number of viable cells, and in LB medium containing FOS $(128 \mu \mathrm{g} / \mathrm{mL})$ and incubated at $37^{\circ} \mathrm{C}$ (Castaneda-Garcia et al., 2009). Subsequently, CFUs were counted for determination of mutant frequencies (mutants/viable cells). The relative increase between induced and spontaneous mutagenesis is represented here in the form 
TABLE 1 | Clinical isolates and reference strain used in this study.

\begin{tabular}{|c|c|c|c|c|c|}
\hline Strain & Year of isolation & Body site & Sequence type & GenBank accession numbers & Analysis performed \\
\hline PA14-UCBPP & 1995 & Wound & 253 & NC_008463 & Genome analysis \\
\hline HIAE_PA01 & 2011 & Blood & 455 & QBET00000000 & Genome analysis \\
\hline HIAE_PAO2 & 2012 & Blood & 381 & QBES00000000 & Genome analysis \\
\hline HIAE_PA05 & 2013 & Blood & 498 & QBER00000000 & Genome analysis \\
\hline HIAE_PA06 & 2014 & Blood & 231 & QBEQ01000000 & $\begin{array}{l}\text { Mutagenesis, MIC of CIP } \\
\text { and genome analysis }\end{array}$ \\
\hline HIAE_PA07 & 2015 & Blood & 252 & QBEP00000000 & Genome analysis \\
\hline HIAE_PA08 & 2015 & Bronchoalveolar lavage & New & QBEO00000000 & Genome analysis \\
\hline HIAE_PA09 & 2015 & Blood & 245 & QBEN00000000 & Genome analysis \\
\hline HIAE_PA10 & 2015 & Bronchoalveolar lavage & 2235 & QBEM01000000 & $\begin{array}{l}\text { Mutagenesis, MIC of CIP } \\
\text { and genome analysis }\end{array}$ \\
\hline HIAE_PA11 & 2015 & Bronchoalveolar lavage & 244 & QBEL01000000 & $\begin{array}{l}\text { Mutagenesis, MIC of CIP } \\
\text { and genome analysis }\end{array}$ \\
\hline HIAE_PA12 & 2015 & Blood & 10 & QBEK01000000 & $\begin{array}{l}\text { Mutagenesis, MIC of CIP } \\
\text { and genome analysis }\end{array}$ \\
\hline HIAE_PA13 & 2015 & Blood & 244 & QBEJ00000000 & Genome analysis \\
\hline HIAE_PA14 & 2015 & Bronchoalveolar lavage & 1290 & QBEI01000000 & $\begin{array}{l}\text { Mutagenesis, MIC of CIP } \\
\text { and genome analysis }\end{array}$ \\
\hline HIAE_PA15 & 2016 & Blood & 1993 & QBEH01000000 & $\begin{array}{l}\text { Mutagenesis, MIC of CIP } \\
\text { and genome analysis }\end{array}$ \\
\hline HIAE_PA16 & 1994 & Bronchoalveolar lavage & 606 & QBEG00000000 & Genome analysis \\
\hline HIAE_PA17 & 1995 & Tracheal secretion & 235 & QBEF00000000 & Genome analysis \\
\hline HIAE_PA18 & 1995 & Bronchoalveolar lavage & 348 & QBEE00000000 & Genome analysis \\
\hline HIAE_PA19 & 1995 & Tracheal secretion & 235 & QBED00000000 & Genome analysis \\
\hline HIAE_PA20 & 1997 & Tracheal secretion & 235 & QBEC00000000 & Genome analysis \\
\hline HIAE_PA21 & 1998 & Tracheal secretion & 253 & QBEB00000000 & Genome analysis \\
\hline
\end{tabular}

Sequence types were obtained by Multilocus Sequence Typing (MLST; Brüggemann et al., 2018).

of fold-change. Fifteen biological replicates were performed for each strain.

\section{Growth Curves}

For bacterial growth curves a single colony was inoculated into liquid $\mathrm{LB}$ medium and incubated at $37^{\circ} \mathrm{C}, 200 \mathrm{rpm}$ for $18 \mathrm{~h}$. The next day, the cultures were diluted to an $\mathrm{OD}_{600}$ of 0.005 , and measurements were collected every 30 min during exponential growth. For the growth curves in the presence of with sub-inhibitory concentrations of CIP, the same procedure was performed, however, upon reaching $\mathrm{OD}_{600}$ of 0.25 , CIP was added to the medium at the respective concentration. The bacterial growth rates were estimated as previously described by Hall et al. (2014) using the formula $\ln \left(N_{\mathrm{t}}-N_{0}\right)=\alpha\left(t_{\mathrm{t}}-\mathrm{t}_{0}\right)$, where $N=$ number of cells at time and $\alpha=$ first-order growth rate constant or the growth rate. In this case, $\alpha$ represent the slope of $\ln N$ versus $t$ or $\ln$ OD versus $t$ (Hall et al., 2014). Here, we calculated the growth rate in the exponential phase (120-270 min).

\section{Analysis of Genome Sequences}

We selected genes previously described as overexpressed in $P$. aeruginosa under sub-inhibitory concentrations of CIP and involved in bacterial adaptive response under stress conditions (Blazquez et al., 2006; Cirz et al., 2006). The nucleotide coding sequences (CDSs) of $\operatorname{din} B, d n a E 2, i m u B, i m u A, \operatorname{rec} A$, lexA, $\operatorname{rec} N$, and $\operatorname{rec} X$ genes and their respective putative promoter regions were extracted from the genomes of the clinical isolates and compared to respective sequences from PA14-UCBPP by sequence alignment using the BLAST tool. Putative promoter regions were predicted using the software BPROM (Softberry Inc., Mount Kisco, NY, United States ${ }^{1}$ ). The upstream region (500 bp) of each gene was inspected and promoter regions were selected as described by Cebrián et al. (2014); in addition, LexA-binding sites, previously predicted by Cirz et al. (2006) were inspected in the strains. For the protein CDSs, to assess the possible impact of SNPs in protein function, the amino acid sequences were generated and aligned using the ClustalX2 program. Only common amino acid changes to all clinical isolates in relation to the PA14-UCBPP reference strain were considered for the purpose of this study.

We also performed protein analysis, evaluating common elements among clinical isolates that differed from the reference strain using data previously generated by our group (Brüggemann et al., 2018). All genomes of the strains used in this study were searched for $u m u D C$-like sequences, using the studied $u m u D C$ of $E$. coli as query.

\footnotetext{
${ }^{1}$ http://linux1.softberry.com
} 


\section{RESULTS}

\section{Clinical Isolates Treated With Ciprofloxacin Showed Lower Survival and Mutagenesis Induced by Sub-Lethal Doses of CIP When Compared to PA14-UCBPP}

All strains used in this study were susceptible to CIP, with MIC, in vitro, of $0.125 \mu \mathrm{g} / \mathrm{mL}$, with exception HIAE_PA11 with MIC of $0.06 \mu \mathrm{g} / \mathrm{mL}$. Mutagenesis induced by sub-MIC CIP were lower in clinical isolates than in PA14-UCBPP (Figure 1). Sub-MIC CIP induced 10-fold mutagenesis in the reference line PA14-UCBPP, similar to that reported in the literature for PAO1 (Jorgensen et al., 2013; Torres-Barcelo et al., 2015; Wassermann et al., 2016; Valencia et al., 2017). By contrast, the highest induction in clinical isolates was approximately threefold in HIAE_PA14 and HIAE_PA15. This low mutagenesis rate was surprising, since mutagenesis in clinical strains could contribute to their adaptation in the hospital environment (Rodriguez-Rojas et al., 2013). To further investigate these findings, we determined the growth curve (optical density, $\mathrm{OD}_{600 \mathrm{~nm}}$ ) for all strains in $\mathrm{LB}$ medium at $37^{\circ} \mathrm{C}$, with and without CIP.

Without treatment, the growth curves and the growth rate of clinical isolates and the reference strain were similar (Figure 2 and Table 2) and are similar to the growth curve presented for PAO1 in the literature: the lag phase takes approximately $2 \mathrm{~h}$, followed by the $\log$ phase to about $4-6 \mathrm{~h}$ growth, and then steady state occurs (Lauridsen et al., 2017). However, after exposure to sub-MIC CIP, the PA14-UCBPP reference strain reached a higher OD than the clinical isolates, revealing a lower replication and/or higher mortality of clinical strains relative to the reference strain (Figure 3 and Table 2). In view of the results observed in this work, we conclude that exposure to CIP leads to different behavior patterns between clinical isolates and the reference strain.

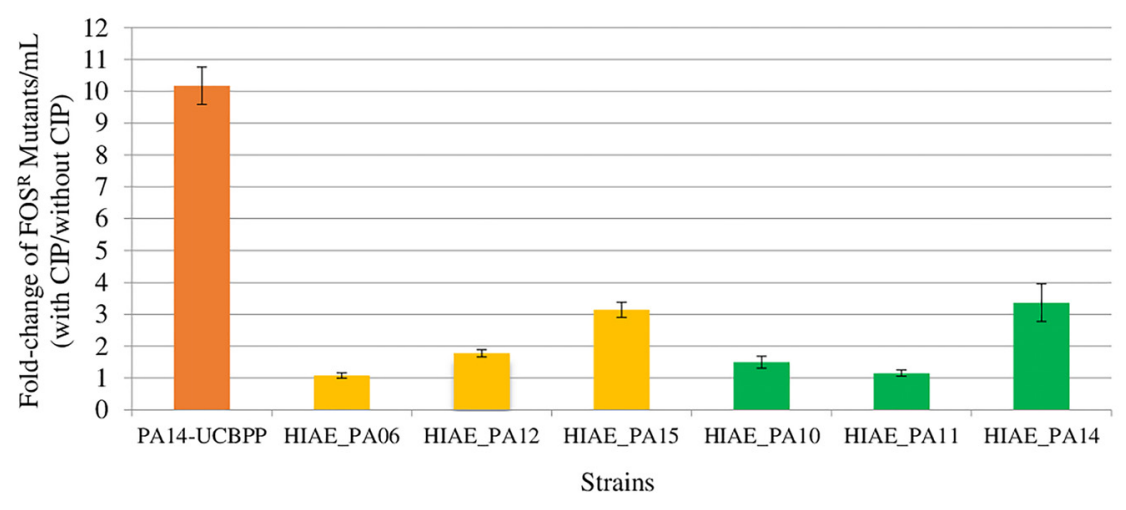

FIGURE 1 | Induced mutagenesis (fold-change) following treatment with sub-inhibitory concentrations of CIP for PA14-UCBPP and six clinical isolates. Sub-inhibitory concentrations of CIP were $0.03 \mu \mathrm{g} / \mathrm{mL}$ for HIAE_PA11 and $0.06 \mu \mathrm{g} / \mathrm{mL}$ for the other strains. The orange bar corresponds to the reference strain PA14-UCBPP, the yellow bars correspond to the blood culture isolates and the green bars correspond to the bronchoalveolar lavage isolates. $N=15$.
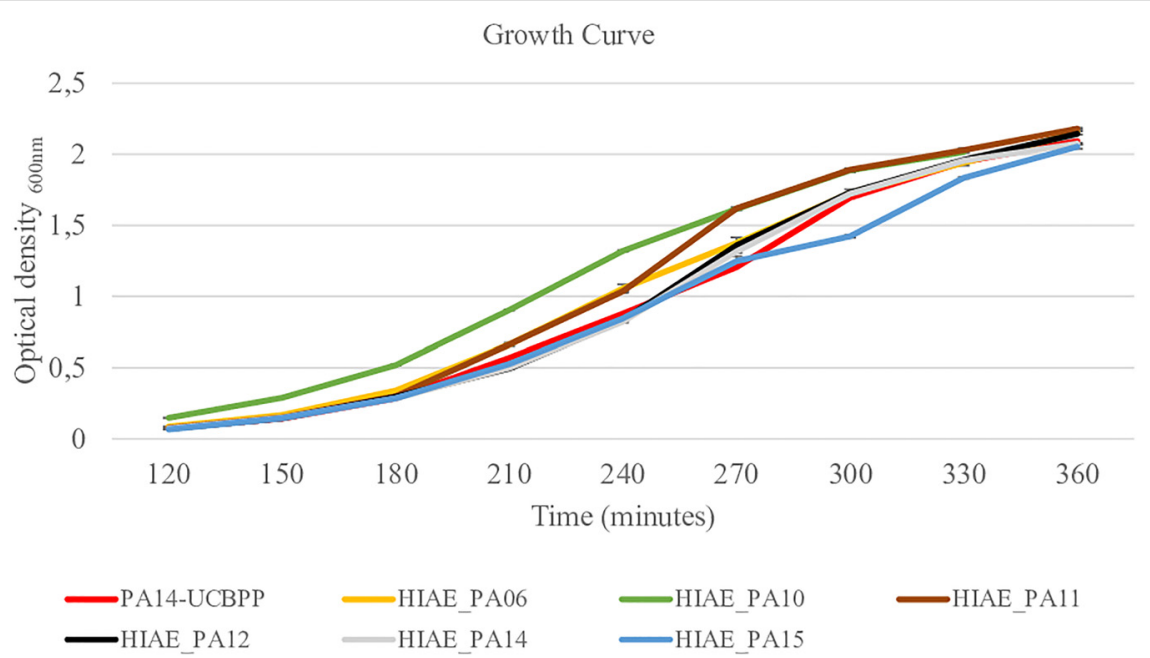

FIGURE 2 | Growth curves for reference strain PA14-UCBPP and clinical isolates. N = 10. 


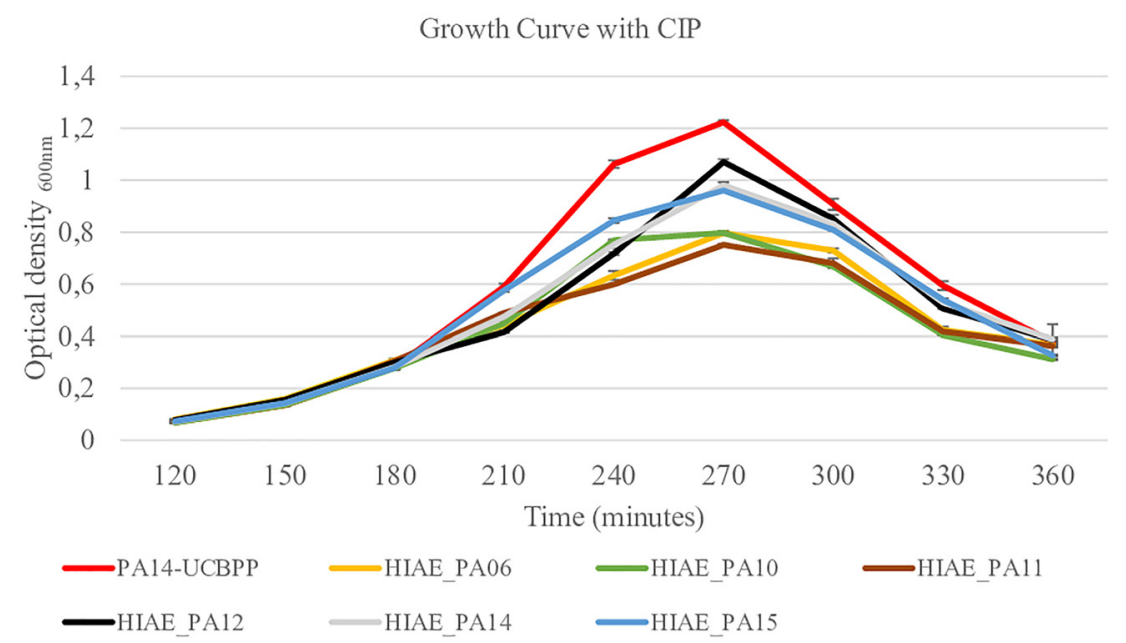

FIGURE 3 | Growth curves for reference strain PA14-UCBPP and clinical isolates following treatment with sub-inhibitory concentrations of CIP. Sub-inhibitory concentrations of CIP were $0.03 \mu \mathrm{g} / \mathrm{mL}$ for HIAE_PA11 and $0.06 \mu \mathrm{g} / \mathrm{mL}$ for the other strains and CIP was added when OD 600 reached 0.25 (at 180 min). $N=10$.

TABLE 2 | Growth rates for the clinical strains and PA14-UCBPP reference strain in exponential phase in the presence and absence of CIP.

\begin{tabular}{lccccccc}
\hline & PA14-UCBPP & HIAE_06 & HIAE_10 & HIAE_11 & HIAE_12 & HIAE_14 & HIAE_15 \\
\hline GR without CIP & 0.018 & 0.018 & 0.019 & 0.020 & 0.020 & 0.019 \\
GR with CIP & 0.019 & 0.015 & 0.016 & 0.015 & 0.017 & 0.017 \\
\hline
\end{tabular}

GR: Growth rate.

We then performed genome comparisons focused on genes previously associated with bacterial adaptive responses under stress conditions. Such genetic alterations could be implicated in the phenotype observed here (Figure 1).

\section{Sequence Analysis of Adaptive Response-Related Genes Reveals Differences in ImuB Protein Between PA14-UCBPP and Clinical Isolates}

The sequence similarity in the adaptive response-related genes $\operatorname{din} B, \operatorname{dnaE2}$, iтuB, imuA, recA, lexA, $\operatorname{rec} N$, and $\operatorname{rec} X$ between the reference strain PA14-UCBPP and clinical isolates ranged from 98 to $100 \%$; the total number of SNPs is reported in Table 3 .

TABLE 3 | Number of SNPs present in adaptive-response related genes of clinical isolates used in this study compared to PA14-UCBPP strain.

PA14 genes Gene HIAE_6 HIAE_10 HIAE_11 HIAE_12 HIAE_14 HIAE_15

\begin{tabular}{lcccccc}
\hline PA14_52310 dinB & 11 & 11 & 10 & 9 & 14 & 12 \\
PA14_55610 dnaE2 & 32 & 36 & 41 & 23 & 34 & 39 \\
PA14_55600 imuB & 25 & 22 & 23 & 25 & 25 & 22 \\
PA14_55590 imuA & 9 & 11 & 22 & 6 & 12 & 11 \\
PA14_17530 recA & 6 & 6 & 5 & 10 & 4 & 6 \\
PA14_25160 lexA & 3 & 3 & 22 & 0 & 2 & 3 \\
PA14_63010 recN & 18 & 24 & 18 & 8 & 20 & 11 \\
PA14_17540 recX & 5 & 5 & 5 & 12 & 5 & 5
\end{tabular}

To assess the possible impact of these SNPs in mutagenesis following treatment at sub-MIC CIP, the amino acid sequences were compared (Table 4). Of the eight genes evaluated, six harbored silent mutations. The most affected CDS was imuB, with consequent 12 amino acid changes; RecX showed one amino acid exchange. The $i m u B$ gene is part of the $i m u A B$ dnaE2 or $i m u A B C$ operon, and it is present in bacteria that do not have $u m u D C$, such as Pseudomonas spp., M. tuberculosis and C. crescentus (Boshoff et al., 2003; Galhardo et al., 2005; Koorits et al., 2007; Warner et al., 2010). In E. coli, umuDC encodes for PolV, an errorprone polymerase that participates in of TLS DNA (Kato and Shinoura, 1977; Caillet-Fauquet and Maenhaut-Michel, 1988). The inactivation of $u m u D C$ in $E$. coli and $i m u A B$ dnaE2 in other bacteria are related to the decrease in damage-induced mutagenesis, and are therefore believed to be homologous in

TABLE 4 | Common amino acid changes to all clinical isolates in relation to the PA14-UCBPP in adaptive-response related genes.

\begin{tabular}{lc}
\hline recA & - \\
lexA & - \\
imuA & - \\
imuB & N21S; K147R; MRTTQ $\rightarrow$ LANSH (149 TO 153); NIS $\rightarrow$ GLA (155 TO \\
& $157) ;$ H166R; T304A \\
dnaE2 & - \\
$\operatorname{din} B$ & - \\
$\operatorname{recN}$ & - \\
$\operatorname{recX}$ & S149G
\end{tabular}


function and important for induced mutagenesis (Napolitano et al., 2000; Galhardo et al., 2005; Warner et al., 2010). We considered using protein homology to assess a possible impact of the alteration found in ImuB on its function, but no structures with sufficient homology were found in the Protein Data Bank ${ }^{2}$.

The rec $X$ gene is defined as rec $A$ co-regulator in $P$. aeruginosa and its inactivation is related to $r e c A$ overexpression that may be lethal for the cell (Sano, 1993). Both, $\operatorname{recX}$ and imuAB dnaE2 are activated by the SOS response and expressed in $P$. aeruginosa against DNA damage (Blazquez et al., 2006; Cirz et al., 2006). Although the consequences of the specific mutations in these genes remain unclear, it can be hypothesized that part of the survival phenotype observed here may be due to these alterations.

We then aimed to identify alteration in the predicted promoter regions that could have implications in gene expression regulation of these genes (Table 5). The nucleotide sequence for the predicted promoter region for $\operatorname{din} B$ was identical for all clinical isolates except for one SNP ( $C$ to $T$ ) at position 52 relative to $\operatorname{din} B$ transcription start codon when compared to the reference strain. For lexA we observed a SNP (C to T) at position -51 relative to lexA transcription start codon for strains HIAE_PA06, HIAE_PA10, HIAE_PA14 and HIAE_PA15. For strain HIAE_PA11 the sequence of nucleotides CGCCTC changed to GCGCAG at position -55 to -50 relative to lexA transcription start codon. However, all SNPs found in both lexA and $\operatorname{din} B$ putative promoters were not within -10 or -35 regions, and should not, therefore, have an effect on RNA polymerase binding. The conserved -10 and -35 sequences are essential for the recognition and binding of $\sigma_{4}$ and $\sigma_{2}$ factors, respectively, being essential for gene expression (Arthur and Burgess, 1998; Campbell et al., 2003; Geszvain et al., 2004).

We also investigated potential SNPs in the LexA-binding sites upstream of genes $\operatorname{din} B, i m u A, i m u B, \operatorname{dnaE2}, \operatorname{rec} A, \operatorname{rec} X$, lexA, and $\operatorname{rec} N$ that were previously predicted (Cirz et al., 2006). No SNPs could be found with one exception: strain HIAE_PA06 carries a SNP in an essential nucleotide position of the LexA-binding motif upstream of $\operatorname{rec} N$.

${ }^{2}$ https://www.rcsb.org/

\section{Presence of umuDC-Like Sequences in Clinical Isolates of $P$. aeruginosa}

Despite the previous notion that $u m u D C$ genes are absent from most $P$. aeruginosa strains (Abella et al., 2004; Erill et al., 2006; Koorits et al., 2007), we searched all clinical isolates of our cohort that were previously sequenced (Brüggemann et al., 2018) for homologs, using E. coli's UmuC and UmuD amino acid sequences as query (Rybenkov, 2014). Interestingly, six out of 20 strains harbored sequences highly similar to UmuC (HIAE_PA01, HIAE_PA05, HIAE_PA07, HIAE_PA10, HIAE_PA13, and HIAE_PA16). Five of these strains also encoded a homolog of $\mathrm{UmuD}$; the gene $u m u D$ was present in close vicinity to $u m u C$ in the five strains (Figure 4). Only in one strain, HIAE_PA10, the $u m u D C$ genes were organized in a putative operon. We wanted to determine the frequency of $u m u C$ and $u m u D$ in other strains of $P$. aeruginosa. Therefore, all strains with known completely closed genome sequences $(n=214)$ were searched, using $u m u C$ and $u m u D$ sequences from strain HIAEPA10 as query. Out of 214 strains, 41 and 40 strains were $u m u C$ and $u m u D$-positive, respectively. Only 19 strains contained both, $u m u C$ and $u m u D$ ( $9 \%$ of all strains). This confirms that the presence of $u m u D C$ is rare among $P$. aeruginosa isolates.

Further inspection of the genomic region revealed that the $u m u D C$-like sequences were part of the flexible genome, i.e., in genomic islands that are inserted into the core genome (Figure 4). Interestingly, the genomic region harboring $u m u D C$ varied strongly in all six strains, indicating that $u m u D C$ was acquired horizontally in different evolutionary events. Those events possibly included transduction, as judged from the presence of phage-like genes in the vicinity of $u m u D C$. Another interesting observation was the association of the $u m u C$ gene with a gene encoding a putative mercury resistance protein in two strains (HIAE_PA05 and HIAE_PA16). In previous studies it was found that mercury resistance genes are located on mobile genetic elements such as plasmids and transposons in Pseudomonas aeruginosa and other Pseudomonas species (Hernández-Ramírez et al., 2018; Kottara et al., 2018). To know more about the occurrence of mercury resistance, we checked the 214 complete $P$. aeruginosa genomes: a gene for putative mercury resistance is

TABLE 5 | SNPs identified in the putative promoter region of adaptive-response related genes of clinical isolates compared to PA14-UCBPP strain.

\begin{tabular}{|c|c|c|c|c|c|c|}
\hline Promoter of Gene & HIAE_6 & HIAE_10 & HIAE_11 & HIAE_12 & HIAE_14 & HIAE_15 \\
\hline $\operatorname{din} B$ & $\begin{array}{c}\mathrm{C} \text { to } \mathrm{T} \text { at } \\
\text { position }-52\end{array}$ & $\begin{array}{c}\mathrm{C} \text { to } \mathrm{T} \text { at } \\
\text { position }-52\end{array}$ & $\begin{array}{c}\mathrm{C} \text { to } \mathrm{T} \text { at position } \\
-52\end{array}$ & $\begin{array}{c}\mathrm{C} \text { to } \mathrm{T} \text { at } \\
\text { position }-52\end{array}$ & $\begin{array}{c}\mathrm{C} \text { to } \mathrm{T} \text { at } \\
\text { position }-52\end{array}$ & $\begin{array}{c}\mathrm{C} \text { to } \mathrm{T} \text { at } \\
\text { position }-52\end{array}$ \\
\hline dnaE2 & - & - & - & - & - & - \\
\hline \multicolumn{7}{|l|}{ imuB } \\
\hline \multicolumn{7}{|l|}{ imuA } \\
\hline recA & - & - & - & - & - & - \\
\hline \multicolumn{7}{|l|}{ recX } \\
\hline lexA & $\begin{array}{c}\text { C to T at } \\
\text { position }-51\end{array}$ & $\begin{array}{c}\mathrm{C} \text { to } \mathrm{T} \text { at } \\
\text { position }-51\end{array}$ & $\begin{array}{c}\text { CGCCTC to } \\
\text { GCGCAG at } \\
\text { position }-55 \text { to }-50\end{array}$ & - & $\begin{array}{c}\mathrm{C} \text { to } \mathrm{T} \text { at } \\
\text { position }-51\end{array}$ & $\begin{array}{c}\mathrm{C} \text { to } \mathrm{T} \text { at } \\
\text { position }-51\end{array}$ \\
\hline
\end{tabular}

$\operatorname{rec} N$

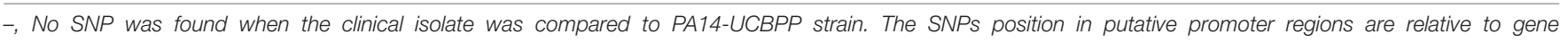
transcription start codon. 


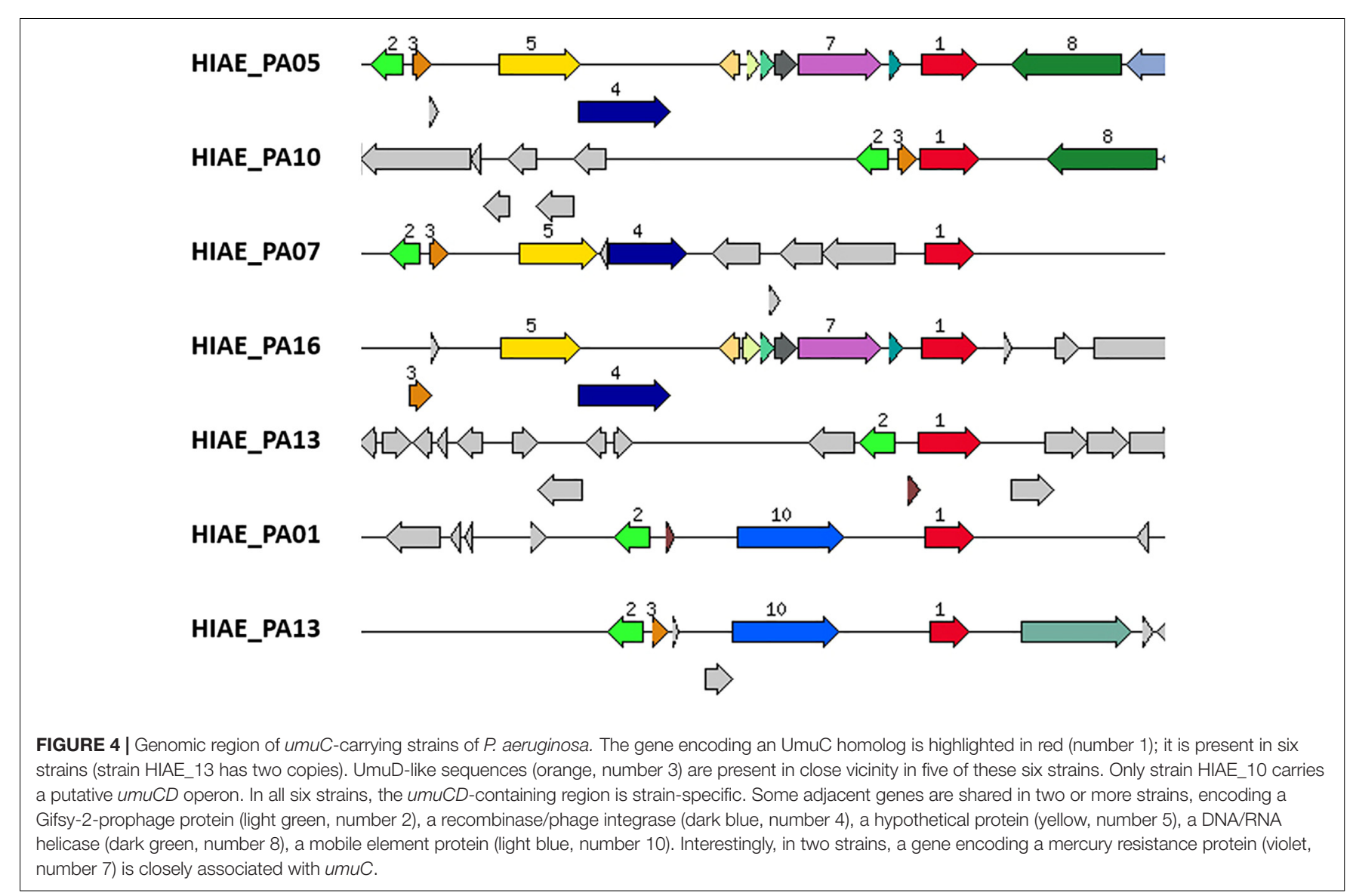

found in 82 strains ( $38 \%$ of all strains). Interestingly, the mercury resistance gene was more often found in $u m u C D$-positive strains [52\% (10/19 strains)]. This underlines that umuCD is encoded within a flexible genomic region that can contain other fitness genes of the flexible gene pool.

\section{Presence of a Bacteriocin, Pyocin S2, in Clinical Isolates}

It is interesting to note that RecA and LexA activities against DNA damage is not restricted to mutagenic response, but may also lead to the induction of phages and bacteriocins that decrease cell viability (Matsui et al., 1993; Fornelos et al., 2016). In order to investigate this additional aspect, we performed protein analysis comparing the clinical isolates and PA14-UCBPP: an antimicrobial bacteriocin (Pyocin S2) was present in all clinical isolates but absent in PA14-UCBPP. The antimicrobial protein Pyocin S2 is produced by $P$. aeruginosa for competition under stress conditions and may lead to cell death and, consequently, may interfere with mutagenesis (Okawa et al., 1973; Ohkawa et al., 1980; Michel-Briand and Baysse, 2002).

\section{DISCUSSION}

In view of the results observed in this work, we conclude that exposure to CIP leads to different behavioral patterns between clinical isolates and the reference strain PA14-UCBPP. Isolating bacteria from an infectious condition and subjecting it to laboratory monocultures may cause these strains to fail to express or lose genetic elements essential for survival in vivo and to express other genes necessary for in vitro survival (Ochman et al., 2000; Hayashi et al., 2001; Liang et al., 2001; Fux et al., 2005). The well-studied reference strains $P$. aeruginosa PAO1 (isolation year, 1955) and PA14-UCBPP (isolation year, 1995) have been sub-cultured for years since their first isolation, which has led to microevolution, possibly leading to new phenotypes (Holloway, 1955; Rahme et al., 1995; Klockgether et al., 2010; Cramer et al., 2011). In P. aeruginosa, these differences have been reported, for example, in the form of decreased ability to form biofilm by PAO1 and PA14-UCBPP relative to fresh clinical isolates, and in mutations that confer changes from non-mucoid to mucoid phenotypes, often found in $P$. aeruginosa isolates newly isolated but rarely detected under standard laboratory conditions (Schurr et al., 1996; Drenkard and Ausubel, 2002). In fact, the great genetic flexibility of $P$. aeruginosa represents a great concern regarding the reproducibility of the phenotypes observed in clinical strains compared with reference strains (Fux et al., 2005; Gaillard et al., 2011; Sidorenko et al., 2017). Also, the differences in phenotype between reference and clinical strains, and between in vivo and in vitro conditions, have been detailed for several bacteria, such as E. coli, Staphylococcus aureus, Bordetella pertussis, Vibrio sp., Salmonella sp. in which changes in 
biofilm production, virulence factors, growth rates, morphology and gene expression have already been observed (Lenski and Travisano, 1994; Edwards et al., 2002; Somerville et al., 2002; Reisner et al., 2006; Davidson et al., 2008; Gaillard et al., 2011; Ruwandeepika et al., 2011).

In our study, these differences are reported in phenotypic and genotypic characteristics. Both induced mutagenesis and replication rates and/or higher mortality of clinical strains as compared with the reference strain can be related to specific mutations in adaptive response-related genes such as imuB and $\operatorname{rec} X$, and the presence of Pyocin S2. The antimicrobial protein Pyocin S2 is produced by $P$. aeruginosa and may be advantageous under conditions when iron levels are low (Okawa et al., 1973; Ohkawa et al., 1980; Michel-Briand and Baysse, 2002). In fact, the levels of this bacteriocin are usually low, but under genotoxic stress it is induced. Similar to the SOS regulon, it is activated upon DNA damage leading to $\operatorname{rec} A$ activation and PrtR repressor self-cleavage triggering prt $N$ expression, necessary for the expression of the S, R, and F type pyocins (Matsui et al., 1993). Even though these mechanisms are activated by the same stimulus, and probably interact simultaneously with RecA co-protease, they trigger opposite responses. The activation of pyocins may lead to the reduction of resistance to genotoxic agents, such as antimicrobials, while the activation of the SOS response is related to the induction of low fidelity polymerases that participate in the TLS, subject to errors during replication, and therefore it is involved in mutagenic response in bacteria (Cirz et al., 2006; Penterman et al., 2014). Thus, Pyocin S2 present in all clinical genome strains but absent in PA14-UCBPP could play a role in viability and in the phenotype of mutagenesis under CIP sub-MIC observed for clinical isolates. The expression of this pyocin could lead to cell death and, consequently, no induction of mutagenesis. It is beyond the scope of this work to explore the function of SNPs found in $i m u B$ and $r e c X$, and the precise level of activity of Pyocin S2 in clinical isolates, but our results suggest that these genetic differences may be implicated in reduced mutagenesis under sub-MIC CIP and in survival rates.

Another important characteristic observed in our study is the presence of $u m u D C$-like sequences in $P$. aeruginosa isolates. These sequences were found more frequently than anticipated, and in contrast with the two widely used laboratory strains PA14-UCBPP and PAO1. In fact, we are aware of only one study that has previously described an $u m u D$-positive $P$. aeruginosa strain (Diaz-Magana et al., 2015); it was found that $u m u D$ was located on the conjugative plasmid pUM505, originally isolated from a clinical strain (Cervantes et al., 1990). Interestingly, it was shown that UmuD participates in the regulation of SOS gene expression; it was suggested that

\section{REFERENCES}

Abella, M., Erill, I., Jara, M., Mazón, G., Campoy, S., and Barbé, J. (2004). Widespread distribution of a lexA-regulated DNA damage-inducible multiple gene cassette in the Proteobacteria phylum. Mol. Microbiol. 54, 212-222. doi: $10.1111 / \mathrm{j} .1365-2958.2004 .04260 . \mathrm{x}$ it functions as an anti-SOS effector (Diaz-Magana et al., 2015). Besides, the plasmid pUM505 also confers resistance to inorganic mercury. This suggests that metal resistance markers and umuCD could be physically linked, at least in some strains, on mobile genetic elements. This could be confirmed here for mercury resistance, as $u m u C D$-positive strains are frequently also carrying mercury resistance determinants. The presence of $u m u D C$ and Pyocin S2 in a clinical isolate highlights the dynamics in the exchange of genetic elements between bacterial strains in a clinical setting and the phenotypic results reveals the need for caution when extrapolating results found in laboratory-adapted reference strains to clinical isolates, especially when it comes to new treatment options and therapeutic alternatives.

\section{DATA AVAILABILITY}

The datasets generated for this study can be found in GenBank, NC_008463 QBEQ01000000, QBEM01000000, QBEL01000000, QBEK01000000, QBEI01000000, and QBEH01000000.

\section{AUTHOR CONTRIBUTIONS}

LM, RG, and PS conceived the study. LM carried out the experiments and analysis with support from RS and AS. LM and $\mathrm{HB}$ carried out the genome analysis. PK and MM were responsible for the clinical isolates maintenance and typing. $\mathrm{LM}, \mathrm{HB}$, and PS interpreted the results. LM and PS wrote the manuscript with contributions from HB and RG. PS supervised the project.

\section{FUNDING}

LM was supported by the Hospital Israelita Albert Einstein fellowship and by grant 2015/18886-0, São Paulo Research Foundation (FAPESP). RS was supported by the CAPES (Coordenacao de Aperfeicoamento de Pessoal de Nivel Superior) fellowship. This work was supported in part by grant 2017/224308, São Paulo Research Foundation (FAPESP).

\section{ACKNOWLEDGMENTS}

The authors gratefully acknowledge the Clinical Laboratory team at Hospital Israelita Albert Einstein for their support, and Aline Silva Muniz and Martin Hoberman for technical assistance.

Andersson, D. I., and Hughes, D. (2014). Microbiological effects of sublethal levels of antibiotics. Nat. Rev. Microbiol. 12, 465-478. doi: 10.1038/ nrmicro3270

Arthur, T. M., and Burgess, R. R. (1998). Localization of a sigma 70 binding site on the N terminus of the Escherichia coli RNA polymerase B' subunit. J. Biol. Chem. 273, 31381-31387. doi: 10.1074/jbc.273.47.31381 
Baharoglu, Z., and Mazel, V. (2011). Vibrio cholerae triggers SOS and mutagenesis in response to a wide range of antibiotics: a route towards multiresistance. Antimicrob. Agents Chemother. 55, 2438-2441. doi: 10.1128/aac.01549-10

Bhagirath, A. Y., Li, Y., Somayajula, D., Dadashi, M., Badr, S., and Duan, K. (2016). Cystic fibrosis lung environment and Pseudomonas aeruginosa infection. BMC Pulm. Med. 16:174. doi: 10.1186/s12890-016-0339-5

Blazquez, J., Gomez-Gomez, J. M., Oliver, A., Juan, C., Kapur, V., and Martin, S. (2006). PBP3 inhibition elicits adaptive responses in Pseudomonas aeruginosa. Mol. Microbiol. 62, 84-99. doi: 10.1111/j.1365-2958.2006.05366.x

Boshoff, H. I., Reed, M. B., Barry, C. E., and Mizrahi, V. (2003). DnaE2 polymerase contributes to in vivo survival and the emergence of drug resistance in Mycobacterium tuberculosis. Cell 113, 183-193. doi: 10.1016/S0092-8674(03) 00270-8

Brüggemann, H., Migliorini, L. B., Sales, R. O., Koga, P. C. M., Souza, A. V., Jensen, A., et al. (2018). Comparative genomics of nonoutbreak Pseudomonas aeruginosa strains underlines genome plasticity and geographic relatedness of the global clone ST235. Genome Biol. Evol. 10, 1852-1857. doi: 10.1093/gbe/ evy139

Caillet-Fauquet, P., and Maenhaut-Michel, G. (1988). Nature of the SOS mutator activity: genetic characterization of untargeted mutagenesis in Escherichia coli. Mol. Gen. Genet. 213, 491-498. doi: 10.1007/bf00 339621

Campbell, E. A., Tupy, J. L., Gruber, T. M., Wang, S., Sharp, M. M., Gross, C. A., et al. (2003). Crystal structure of Escherichia coli $\sigma \mathrm{E}$ with the cytoplasmic domain of its anti- $\sigma$ RseA. Mol. Cell 11, 1067-1078. doi: 10.1016/s10972765(03)00148-5

Castaneda-Garcia, A., Rodriguez-Rojas, A., Guelfo, J. R., and Blazquez, J. (2009). The glycerol-3-phosphate permease GlpT is the only fosfomycin transporter in Pseudomonas aeruginosa. J. Bacteriol. 191, 6968-6974. doi: 10.1128/jb. 00748-09

Cebrián, R., Rodríguez-Ruano, S., Martínez-Bueno, M., Valdivia, E., Maqueda, M., and Montalbán-López, M. (2014). Analysis of the promoters involved in enterocin AS-48 expression. PLoS One 9:e90603. doi: 10.1371/journal.pone. 0090603

Cervantes, C., Ohtake, H., Chu, L., Misra, T. K., and Silver, S. (1990). Cloning, nucleotide sequence, and expression of the chromate resistance determinant of Pseudomonas aeruginosa plasmid pUM505. J. Bacteriol. 172, 287-291. doi: 10.1128/jb.172.1.287-291.1990

Ciofu, O., Mandsberg, L. F., Bjarnsholt, T., and Hoiby, N. (2010). Genetic adaptation of Pseudomonas aeruginosa during chronic lung infection of patients with cystic fibrosis: strong and weak mutators with heterogeneous genetic backgrounds emerge im $m u c A$ and/or lasR mutants. Microbiology 156, 1108-1119. doi: 10.1099/mic. 0.033993

Cirz, R. T., Chin, J. K., Andes, D. R., Crecy-Lagard, V., Craig, W. A., and Romesberg, F. E. (2005). Inhibition of mutation and combating the evolution of antibiotic resistance. PLoS Biol. 3:e176. doi: 10.1371/journal.pbio.0030176

Cirz, R. T., O'Neill, B. M., Hammond, J. A., Head, S. R., and Romesberg, F. E. (2006). Defining the Pseudomonas aeruginosa SOS response and its role in the global response to the antibiotic ciprofloxacin. J. Bacteriol. 188, 7101-7110. doi: 10.1128/JB.00807-06

Clinical and Laboratory Standards Institute [CLSI] (2016). Methods for Dilution Antimicrobial Susceptibility Tests for Bacteria That Grow Aerobically. Wayne, PA: CLSI.

Cramer, N., Klockgether, J., Wrasman, K., Schmidt, M., Davenport, C. F., and Tummler, B. (2011). Microevolution of the major common Pseudomonas aeruginosa clones $\mathrm{C}$ and PA14 in cystic fibrosis lungs. Environ. Microbiol. 13, 1690-1704. doi: 10.1111/j.1462-2920.2011.02483.x

Davidson, C. J., White, A. P., and Surette, M. G. (2008). Evolutionary loss of the rdar morphotype in Salmonella as a result of high mutation rates during laboratory passage. ISME J. 2, 293-307. doi: 10.1038/ismej. 2008.4

Diaz-Magana, A., Alva-Murillo, N., Chavez-Moctezuma, M. P., Lopez-Meza, J. E., Ramirez-Diaz, M. I., and Cervantes, C. (2015). A plasmid-encoded UmuD homologue regulates expression of Pseudomonas aeruginosa SOS genes. Microbiology 161, 1516-1523. doi: 10.1099/mic.0.000103

Dörr, T., Lewis, K., and Vulić, M. (2009). SOS response induces persistence to fluoroquinolones in Escherichia coli. PLoS Genet. 5:e1000760. doi: 10.1371/ journal.pgen. 1000760
Drenkard, E., and Ausubel, F. M. (2002). Pseudomonas biofilm formation and antibiotic resistance are linked to phenotypic variation. Nature 416, 740-743. doi: $10.1038 / 416740 \mathrm{a}$

Drlica, K., and Zhao, X. (1997). DNA gyrase, topoisomerase IV, and the 4-quinolones. Microbiol. Mol. Biol. Rev. 61, 377-392.

Edwards, R. J., Sockett, R. E., and Brookfield, J. F. (2002). A simple method for genome-wide screening for advantageous insertions of mobile DNAs in Escherichia coli. Curr. Biol. 12, 863-867. doi: 10.1016/s0960-9822(02)00837-0

Elledge, S. J., and Walker, G. C. (1983). Proteins required for ultraviolet light and chemical mutagenesis: identification of the products of the $u m u C$ locus of Escherichia coli. J. Mol. Biol. 164, 175-192.

Erill, I., Campoy, S., Mazon, G., and Barbe, J. (2006). Dispersal and regulation of an adaptive mutagenesis cassette in the bacteria domain. Nucleic Acids Res. 34, 66-77. doi: 10.1093/nar/gkj412

Fornelos, N., Browning, D. F., and Butala, M. (2016). The use and abuse of lexa by mobile genetic elements. Trends Microbiol. 24, 391-401. doi: 10.1016/j.tim. 2016.02.009

Friedberg, E., Walker, G. C., Siede, W., Wood, R. D., Schultz, R. A., and Ellenberger, T. (2006). DNA Repair and Mutagenesis, 2nd Edn. Washington, DC: ASM Press.

Fux, C. A., Shirtliff, M., Stoodley, P., and Costerton, J. W. (2005). Can laboratory reference strains mirror "real-world" pathogenesis? Trends Microbiol. 13, 58-63. doi: 10.1016/j.tim.2004.11.001

Gaillard, M. E., Bottero, D., Castuma, C. E., Basile, L. A., and Hozbor, D. (2011). Laboratory adaptation of bordetella pertussis is associated with the loss of type three secretion system functionality. Infect. Immun. 79, 3677-3682. doi: 10.1128/IAI.00136-11

Galhardo, R. S., Rocha, R. P., Marques, M. V., and Menck, C. F. (2005). An SOSregulated operon involved in damage-inducible mutagenesis in Caulobacter crescentus. Nucleic Acids Res. 33, 2603-2614. doi: 10.1093/nar/gki551

Geszvain, K., Gruber, T. M., Mooney, R. A., Gross, C. A., and Landick, R. (2004). A hydrophobic patch on the flap-tip helix of E. coli RNA polymerase mediates $\sigma 70$ region 4 function. J. Mol. Biol. 343, 569-587. doi: 10.1016/j.jmb.2004.08.063

Gullberg, E., Cao, S., Berg, O. G., Ilbäck, C., Sandegren, L., Hughes, D., et al. (2011). Selection of resistant bacteria at very low antibiotic concentrations. PLoS Pathog. 7:e1002158. doi: 10.1371/journal.ppat.1002158

Hall, B. G., Acar, H., Nandipati, A., and Barlow, M. (2014). Growth rates made easy. Mol. Biol. Evol. 31, 232-238. doi: 10.1093/molbev/mst187

Hayashi, T., Makino, K., Ohnishi, M., Kurokawa, K., Ishii, K., Yokoyama, K., et al. (2001). Complete genome sequence of enterohemorrhagic Escherichia coli O157:H7 and genomic comparison with a laboratory strain K-12. DNA Res. 8, 11-22. doi: 10.1093/dnares/8.1.11

Hernández-Ramírez, K. C., Reyes-Gallegos, R. I., Chávez-Jacobo, V. M., DíazMagaña, A., Meza-Carmen, V., and Ramírez-Díaz, M. I. (2018). A plasmidencoded mobile genetic element from Pseudomonas aeruginosa that confers heavy metal resistance and virulence. Plasmid 98, 15-21. doi: 10.1016/j.plasmid. 2018.07.003

Holloway, B. W. (1955). Genetic recombination in Pseudomonas aeruginosa. Microbiology 13, 572-581. doi: 10.1099/00221287-13-3-572

Jorgensen, K. M., Wassermann, T., Jensen, P. O., Hengzuang, W., Molin, S., Hoiby, N., et al. (2013). Sublethal ciprofloxacin treatment leads to rapid development of high-level ciprofloxacin resistance during long-term experimental evolution of Pseudomonas aeruginosa. J. Antimicrob. Chemother. 57, 4215-4221. doi: $10.1128 /$ aac. $00493-13$

Kato, T., and Shinoura, Y. (1977). Isolation and characterization of mutants of Escherichia coli deficient in induction of mutations by ultraviolet light. Mol. Gen. Genet. 156, 121-131. doi: 10.1007/BF00283484

Klockgether, J., Munder, A., Neugebauer, J., Davenport, C. F., Stanke, F., Larbig, K. D., et al. (2010). Genome diversity of Pseudomonas aeruginosa PAO1 laboratory strains. J. Bacteriol. 192, 1113-1121. doi: 10.1128/jb.01515-09

Koorits, L., Tegova, R., Tark, M., Tarassova, K., Tover, A., and Kivisaar, M. (2007). Study of involvement of ImuB and DnaE2 in stationary-phase mutagenesis in Pseudomonas putida. DNA Repair 6, 863-868. doi: 10.1016/j.dnarep.2007. 01.010

Kottara, A., Hall, J. P., Harrison, E., and Brockhurst, M. A. (2018). Variable plasmid fitness effects and mobile genetic element dynamics across Pseudomonas species. FEMS Microbiol. Ecol. 94:fix172. doi: 10.1093/femsec/fix172

Kummerer, K. (2003). Significance of antibiotics in the environment. J. Antimicrob. Chemother. 52, 5-7. doi: 10.1093/jac/dkg293 
Laureti, L., Ivan, M., and Arnaud, G. (2013). Bacterial responses and genome instability induced by subinhibitory concentrations of antibiotics. Antibiotics 2, 100-114. doi: 10.3390/antibiotics 2010100

Lauridsen, R. K., Sommer, L. M., Johansen, H. K., Rindzevicius, T., Molin, S., Jelsbak, L., et al. (2017). SERS detection of the biomarker hydrogen cyanide from Pseudomonas aeruginosa cultures isolated from cystic fibrosis patients. Sci. Rep. 7:45264. doi: 10.1038/srep45264

Lenski, R. E., and Travisano, M. (1994). Dynamics of adaptation and diversification: a 10,000-generation experiment with bacterial populations. Proc. Natl. Acad. Sci. U.S.A. 91, 6808-6814. doi: 10.1073/pnas.91.15.6808

Liang, X., Pham, X. Q. T., Olson, M. V., and Lory, S. (2001). Identification of a genomic island present in the majority of pathogenic isolates of Pseudomonas aeruginosa. J. Bacteriol. 183, 843-853. doi: 10.1128/JB.183.3.843-853.2001

Mathieu, A., Fleurier, S., Frenoy, A., Dairou, J., Bredeche, M. F., Sanchez-Vizuete, P., et al. (2016). Discovery and function of a general core hormetic stress response in $E$. coli induced by sublethal concentrations of antibiotics. Cell Rep. 17, 46-57. doi: 10.1016/j.celrep.2016.09.001

Matsui, H., Sano, Y., Ishihara, H., and Shinomiya, T. (1993). Regulation of pyocin genes in Pseudomonas aeruginosa by positive (prtN) and negative (prtR) regulatory genes. J. Bacteriol. 175, 1257-1263. doi: 10.1128/jb.175.5.1257-1263. 1993

Michel-Briand, Y., and Baysse, C. (2002). The pyocins of Pseudomonas aeruginosa. Biochimie 84, 499-510. doi: 10.1093/oxfordjournals.jbchem.a129929

Moriarty, T. F., McElnay, J. C., Elborn, J. S., and Tunney, M. M. (2007). Sputum antibiotic concentrations: implications of cystic fibrosis lung infection. Pediatr. Pulmonol. 42, 1008-1017. doi: 10.1002/ppul.20671

Nair, C. G., Chao, C., Ryall, B., and Willians, H. D. (2013). Sub-lethal concentrations of antibiotics incriase mutation frequency in the cystic fibrosis pathogen Pseudomonas aeruginosa. Lett. Appl. Microbiol. 56, 149-154. doi: 10.1111/lam.12032

Napolitano, R., Janel-Bintz, R., Wagner, J., and Fuchs, R. P. (2000). All three SOSinducible DNA polymerases (Pol II, Pol IV and Pol V) are involved in induced mutagenesis. EMBO J. 19, 6259-6265. doi: 10.1093/emboj/19.22.6259

Ochman, H., Lawrence, J. G., and Groisman, E. A. (2000). Lateral gene transfer and the nature of bacterial innovation. Nature 405, 299-304. doi: 10.1038/ 35012500

Ohkawa, I., Shiga, S., and Kageyama, M. (1980). Effect of iron concentration in the growth medium on the sensitivity of Pseudomonas aeruginosa to pyocin S2. J. Biochem. 87, 323-331. doi: 10.1093/oxfordjournals.jbchem.a132740

Okawa, I., Kageyama, M., and Egami, F. (1973). Purification and properties of pyocin S2. J. Biochem. 73, 281-289.

O’Sullivan, D. M., Hinds, J., Butcher, P. D., Gillespie, S. H., and McHugh, T. D. (2008). Mycobacterium tuberculosis DNA repair in response to subinhibitory concentrations of ciprofloxacin. J. Antimicrob. Chemother. 62, 1199-1202. doi: 10.1093/jac/dkn387

Penterman, J., Singh, P. K., and Walker, G. C. (2014). Biological cost of pyocin production during the SOS response in Pseudomonas aeruginosa. J. Bacteriol. 196, 3351-3359. doi: 10.1128/JB.01889-14

Rahme, L. G., Stevens, E. J., Wolfort, S. F., Shao, J., Tompkins, R. G., and Ausubel, F. M. (1995). Common virulence factors for bacterial pathogenicity in plants and animals. Science 268, 1899-1902. doi: 10.1126/science.7604262

Reisner, A., Krogfelt, K. A., Klein, B. M., Zechner, E. L., and Molin, S. (2006). In Vitro biofilm formation of commensal and pathogenic Escherichia coli strains: impact of environmental and genetic factors. J. Bacteriol. 188, 3572-3581. doi: 10.1128/JB.188.10.3572-3581.2006

Reuven, N. B., Arad, G., Maor-Shoshani, A., and Livneh, Z. (1999). The mutagenesis protein UmuC is a DNA polymerase activated by UmuD', RecA, and SSB and is specialized for translesion replication. J. Biol. Chem. 274, 31763-31766. doi: 10.1074/jbc.274.45.31763

Rodriguez-Rojas, A., Rodriguez-Beltran, J., Couce, A., and Blazquez, J. (2013). Antibiotics and antibiotic resistance: a bitter fight against evolution. Int. J. Med. Microbiol. 303, 293-297. doi: 10.1016/j.ijmm.2013.02.004

Ruwandeepika, H. A., Defoirdt, T., Bhowmick, P. P., Karunasagar, I., Karunasagar, I., and Bossier, P. (2011). In vitro and in vivo expression of virulence genes in Vibrio isolates belonging to the Harveyi clade in relation to their virulence towards gnotobiotic brine shrimp (Artemia franciscana). Environ. Microbiol. 13, 506-517. doi: 10.1111/j.1462-2920.2010.02354.x

Rybenkov, V. V. (2014). Maintenance of chromosome structure in Pseudomonas aeruginosa. FEMS Microbiol. Lett. 356, 154-165. doi: 10.1111/1574-6968.12478

Sano, Y. (1993). Role of the $r e c A$-related gene adjacent to the $r e c A$ gene in Pseudomonas aeruginosa. J. Bacteriol. 175, 2451-2454. doi: 10.1128/jb.175.8. 2451-2454.1993

Schurr, M. J., Yu, H., Martinez-Salazar, J. M., Boucher, J. C., and Deretic, V. (1996). Control of AlgU, a member of the sigma E-like family of stress sigma factors, by the negative regulators $\mathrm{MucA}$ and $\mathrm{MucB}$ and Pseudomonas aeruginosa conversion to mucoidy in cystic fibrosis. J. Bacteriol. 178, 4997-5004. doi: 10.1128/jb.178.16.4997-5004.1996

Shinagawa, H., Kato, T., Ise, T., Makino, K., and Nakata, A. (1983). Cloning and characterization of the $u m u$ operon responsible for inducible mutagenesis in Escherichia coli. Gene 23, 167-174. doi: 10.1016/0378-1119(83)948-3

Sidorenko, J., Jatsenko, P., and Kivisaar, M. (2017). Ongoing evolution of Pseudomonas aeruginosa PAO1 sublines complicates studies of DNA damage repair and tolerance. Mutat. Res. 79, 26-37. doi: 10.1016/j.mrfmmm.2017. 03.005

Somerville, G. A., Beres, S. B., Fitzgerald, J. R., DeLeo, F. R., Cole, R. L., Hoff, J. S., et al. (2002). In vitro serial passage of Staphylococcus aureus: changes in physiology, virulence factor production, and agr nucleotide sequence. J. Bacteriol. 184, 1430-1437. doi: 10.1128/jb.184.5.1430-1437.2002

Tang, M., Shen, X., Frank, E. G., O’Donnell, M., Woodgate, R., and Goodman, M. F. (1999). UmuD' 2C is an error-prone DNA polymerase, Escherichia coli pol V. Proc. Natl. Acad. Sci. U.S.A. 96, 8919-8924. doi: 10.1073/pnas.96.16.8919

Thi, T. D., Lopez, E., Rodriguez-Rojas, A., Rodriguez-Beltran, J., Couce, A., Guelfo, J. R., et al. (2011). Effect of recA inactivation on mutagenesis of Escherichia coli exposed to sublethal concentrations of antimicrobials. J. Antimicrob. Chemother. 66, 531-538. doi: 10.1093/jac/dkq496

Tippin, B., Pham, P., and Goodman, M. F. (2004). Error-prone replication for better or worse. Trends Microbiol. 12, 288-295. doi: 10.1016/j.tim.2004.04.004

Torres-Barcelo, C., Kojadinovic, M., Moxon, R., and MacLean, R. C. (2015). The SOS response increases bacterial fitness, but not evolvability, under a sublethal dose of antibiotic. Proc. Biol. Sci. 282:20150885. doi: 10.1098/rspb.2015.0885

Valencia, E. Y., Esposito, F., Spira, B., Blazquez, J., and Galhardo, R. S. (2017). Ciprofloxacin-mediated mutagenesis is suppressed by subinhibitory concentrations of amikacin in Pseudomonas aeruginosa. Antimicrob. Agents Chemother. 61, e2107-e2116. doi: 10.1128/aac.02107-16

Van Bambeke, F., Michot, J. M., Van Eldere, J., and Tulkens, P. M. (2005). Quinolones in 2005: an update. Clin. Microbiol. Infect. 11, 256-280. doi: 10. 1111/j.1469-0691.2005.01131.x

Warner, D. F., Ndwandwe, D. E., Abrahams, G. L., Kana, B. D., Machowski, E. E., Venclovas, C., et al. (2010). Essential roles for imuA'- and imuBencoded accessory factors in DnaE2-dependent mutagenesis in Mycobacterium tuberculosis. Proc. Natl. Acad. Sci. U.S.A. 107, 13093-13098. doi: 10.1073/pnas. 1002614107

Wassermann, T., Meinike, J. K., Ivanyshyn, K., Bjarnsholt, T., Khademi, S. M., Jelsbak, L., et al. (2016). The phenotypic evolution of Pseudomonas aeruginosa populations changes in the presence of subinhibitory concentrations of ciprofloxacin. Microbiology 162, 865-875. doi: 10.1099/mic.0.000273

Conflict of Interest Statement: The authors declare that the research was conducted in the absence of any commercial or financial relationships that could be construed as a potential conflict of interest.

Copyright (c) 2019 Migliorini, Brüggemann, de Sales, Koga, de Souza, Martino, Galhardo and Severino. This is an open-access article distributed under the terms of the Creative Commons Attribution License (CC BY). The use, distribution or reproduction in other forums is permitted, provided the original author(s) and the copyright owner(s) are credited and that the original publication in this journal is cited, in accordance with accepted academic practice. No use, distribution or reproduction is permitted which does not comply with these terms. 